\title{
DIVALENT CATION AND PH DEPENDENCE OF RAT INTRINSIC FACTOR ACTION IN EVERTED SACS AND MUCOSAL HOMOGENATES OF RAT SMALL INTESTINE*
}

\author{
BY VICTOR HERBERT AND WILLIAM B. CASTLE
}

\author{
(From the Thorndike Memorial Laboratory and Second and Fourth (Harvard) Medical \\ Services, Boston City Hospital, and the Department of Medicine, Harvard \\ Medical School, Boston, Mass.)
}

(Submitted for publication June 14, 1961 ; accepted July 20, 1961)

In 1959 it was reported in these pages (1) that hog intrinsic factor concentrate enhanced the uptake of radioactive vitamin $\mathrm{B}_{12}\left(\mathrm{Co}^{60}-\mathrm{B}_{12}\right)$ by everted sacs of rat small intestine in the cold. This enhancement was significantly reduced in the absence of calcium and was reversible to a significant degree by disodium ethylenediamine tetraacetate dihydrate (EDTA) (1), suggesting that intrinsic factor action was calcium-dependent. Disodium EDTA reduced the enhancing effect on radio- $\mathrm{B}_{12}$ uptake of rat intrinsic factor in loops of small intestine in a living rat; calcium EDTA was without such inhibitory effect (2). Other workers, however, threw doubt on the calcium dependence of intrinsic factor action. They reported that gastrectomized rats fed radio- $\mathrm{B}_{12}$ bound to rat gastric juice plus large amounts of disodium EDTA $(3,4)$, and normal rats fed radio- $\mathrm{B}_{12}$ plus disodium or tetrasodium EDTA (5), had normal radio- $\mathrm{B}_{12}$ absorption. These findings, taken with the fact that the in vitro studies did not demonstrate total loss of the effect of intrinsic factor on depletion of calcium, left the concept of the calcium dependence of intrinsic factor action in doubt.

The present report presents the results of a study aimed at resolving this uncertainty, and also at strengthening the evidence $(6,7)$ for the $\mathrm{pH}$ dependence of intrinsic factor action.

\section{MATERIALS AND METHODS}

$C 0^{00}$-labeled vitamin $B_{12}$ and $C 0^{57}$-labeled vitamin $B_{12 .}{ }^{1}$

The $\mathrm{Co}^{\infty}$-labeled vitamin $\mathrm{B}_{12}$ had a specific activity of approximately $1 \mu \mathrm{c}$ per $\mu \mathrm{g}$, and the $\mathrm{Co}^{57}$-labeled vitamin $\mathrm{B}_{12}$

* This work supported in part by Grant A-795 from the National Institutes of Health, Bethesda, Md., and in part by grants from the National Vitamin Foundation and from Eli Lilly \& Co.

1 Kindly provided by Drs. C. Rosenblum, N. Ritter and E. Alpert of Merck Sharp \& Dohme Research Laboratories, West Point, Pa. had a specific activity of approximately $5 \mu \mathrm{c}$ per $\mu \mathrm{g}$. The $\mathrm{pH}$-dependence experiments using everted sacs were performed with $\mathrm{Co}^{57}$-labeled vitamin $\mathrm{B}_{12}$; all other experiments were performed with $\mathrm{Co}^{\circ 0}$-labeled vitamin $\mathrm{B}_{12}$.

Rat intrinsic factor concentrate (RIFC) was prepared as previously described (2).

Rat small intestine everted sac system. The homologous system (RIFC, everted sacs of rat small intestine) used by Strauss and Wilson (8-10) was employed.

Nonfasting male Sprague-Dawley rats were sacrificed. The small intestine was transected at the pylorus and 25 to $50 \mathrm{ml}$ of 0.9 per cent $\mathrm{NaCl}$ was run through it to rinse out particulate content. The small intestine was then stripped free of its mesenteric attachment, transected at its ileal end and everted on a stainless steel rod, $112 \mathrm{~cm}$ long and $1.5 \mathrm{~mm}$ in diameter, with rounded ends. Beginning with its lower end, the rat small intestine was slipped over the rod until a silk ligature could be placed tightly over the ileal end of the intestine, and held in place by a groove in the rod $2 \mathrm{~mm}$ from its end. The intestine was gently and rapidly everted on itself. It was then washed by dipping repeatedly into each of two changes of $200 \mathrm{ml}$ saline, and placed in a petri dish containing 0.9 per cent saline at room temperature.

Individual sacs approximately $4 \mathrm{~cm}$ long were prepared as described by Wilson and Wiseman (11). After being ligated at each end and slightly distended with Krebs-Henseleit bicarbonate (12) containing $200 \mathrm{mg}$ per $100 \mathrm{ml}$ glucose, each sac was dropped into a separate $50-\mathrm{ml}$ Erlenmeyer flask containing $5 \mathrm{ml}$ incubation medium plus $5,000 \mu \mu \mathrm{g}$ of radioactive vitamin $B_{12}$ in 0.5 $\mathrm{ml}$ of 0.9 per cent saline with or without added RIFC. The amount of RIFC used was prepared from $1 / 100$ of a rat stomach, diluted with 0.9 per cent $\mathrm{NaCl}$ to a volume of $0.5 \mathrm{ml}$. This amount of rat stomach was chosen because it produced near maximal enhancement of vitamin $B_{12}$ uptake in this everted sac system. Indeed, tenfold lower or higher amounts of RIFC produced markedly less enhancement, and still larger amounts inhibited radio$B_{12}$ uptake (data not shown).

Immediately after placing each filled everted sac in the medium, the flask was gassed for 60 seconds with 95 per cent $\mathrm{O}_{2}$ and 5 per cent $\mathrm{CO}_{2}$, sealed with a rubber stopper, and shaken ( 96 cycles per minute) at $37^{\circ} \mathrm{C}$ for 1 hour. At the end of this period the sac was removed and rinsed through three changes of 0.9 per cent saline. The ligated ends were then cut off, the sac cut open lengthwise and gently blotted with toilet tissue, weighed, 
and the quantity of its radioactivity determined in a welltype scintillation detector, for which the magnitude of the background averaged 330 counts per minute. In this detector the $\mathrm{Co}^{\infty 0}$-labeled vitamin $\mathrm{B}_{12}$ registered approximately 1 count above background per minute per $\mu \mu \mathrm{g}$, and the $\mathrm{Co}^{\mathrm{bT}}$-labeled vitamin $\mathrm{B}_{12}$ registered approximately 4 counts above background per minute per $\mu \mu \mathrm{g}$.

In all experiments with everted sacs, except those in which the site of intrinsic factor action was studied, the top and bottom 20 per cent of the rat small intestine was discarded and sacs were prepared from the remainder, beginning at its top. This was done because of the minimal-to-absent action of RIFC at top and bottom of the rat small intestine. Each experiment was repeated at least three times in order to ensure validity. Sac length was measured by placing a ruler alongside the unstretched gut, which had been allowed to retract while in 0.9 per cent $\mathrm{NaCl}$ at room temperature in a large petri dish.

Rat small intestine mucosal homogenate system (rat gut homogenate system). Nonfasting 200 to $300 \mathrm{~g}$ male Sprague-Dawley rats were sacrificed. The small intestine was transected at the pylorus, stripped free of its mesenteric attachment, and transected at its ileal end. It was then placed on a long strip of Parafilm, ${ }^{2}$ measured, and the top and bottom 20 per cent discarded. The remaining small intestine was everted, washed free of adherent intestinal contents by dipping repeatedly into each of two changes of 0.9 per cent $\mathrm{NaCl}$, and cut with scissors into roughtly 7 - to $8-\mathrm{cm}$ segments. Each segment was then scraped free of mucosa with two glass slides (one holding the gut in a fixed position, the other used for scraping). The mucosal scrapings from two rats

${ }^{2}$ Marathon Co., division of American Can Co., Menasha, Wis. were combined and placed in $25 \mathrm{ml}$ of 0.9 per cent $\mathrm{NaCl}$ in a $50-\mathrm{ml}$ beaker, shaken vigorously by hand for 10 seconds and then homogenized for 30 seconds in a Waring Blendor. Then, after being centrifuged for $10 \mathrm{~min}-$ utes at 3,000 rpm, the liquid intermediate phase was discarded, leaving together for final suspension both the particulate material that initially floated above the liquid phase and that which sedimented. Sufficient 0.9 per cent $\mathrm{NaCl}$ was added to this rat small intestine homogenate so that $1 \mathrm{ml}$ of the resultant suspension of homogenate could easily be pipetted into each of a series of $50-\mathrm{ml}$ Erlenmeyer flasks. The homogenate prepared from one rat intestine was sufficient for 8 to 14 such flasks.

In the experiments here reported, incubation with rat gut homogenate was performed as with everted sacs, except that the gas phase was air. Freshly prepared rat gut homogenate was used, although thawed frozen homogenate is equally useful in the "assay" of RIFC (data not presented). Incubation was followed by centrifugation for 10 minutes at $3,000 \mathrm{rpm}$. The liquid phase was then removed by pipet, followed by resuspension in and centrifugation from two washes in $10 \mathrm{ml}$ of 0.9 per cent $\mathrm{NaCl}$ containing 10 mmoles $\mathrm{CaCl}_{2}$. The quantity of radioactivity retained by the sedimented rat gut homogenate was then determined in a well-type scintillation detector.

In the studies of $\mathrm{pH}$ dependence of intrinsic factor action, the buffer used consisted of 9 parts Krebs-Ringer solution (13), brought to appropriate $\mathrm{pH}$ with 1 part $0.05 \mathrm{M}$ Tris-(hydroxymethyl) aminomethane-acid maleate$\mathrm{NaOH}$ buffer (14). Immediately after placing each everted sac in the medium, the flasks were gassed with 100 per cent $\mathrm{O}_{2}$ and shaken at $37^{\circ} \mathrm{C}$ for one-half hour. The same incubation system was used for $\mathrm{pH}$-dependence

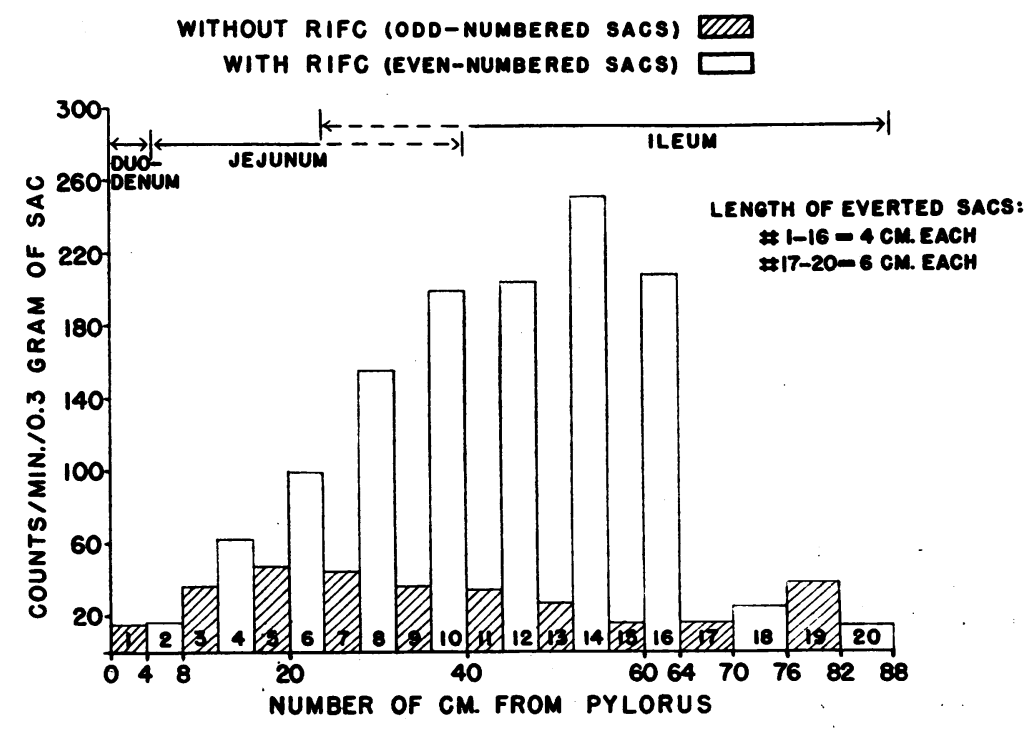

Fig. 1. Absorption of vitamin $B_{12}$ at various levels of the rat SMall INTESTINE in vitro, WITHOUT AND WITH ADDED RAT INTRINSIC FACTOR CONCENTRATE (RIFC). 
TABLE I

Divalent cation dependence of rat intrinsic factor concentrate (RIFC) in augmenting adsorption of $C^{60}-B_{12}$ by everted sacs * and mucosal hamogenates of rat small intestine

\begin{tabular}{|c|c|c|c|c|c|}
\hline Incub. medium $†$ & RIFC & $\begin{array}{c}\mathrm{cpm} / \\
\text { everted sact }\end{array}$ & $\begin{array}{l}\text { Excess counts } \\
\text { over control } \\
\text { sacs }\end{array}$ & $\begin{array}{l}\mathrm{cpm} / \\
\text { aliquot gut } \\
\text { homogenate }\end{array}$ & $\begin{array}{l}\text { Excess counts } \\
\text { over control } \\
\text { homogenate }\end{array}$ \\
\hline $\begin{array}{l}\text { Standard } \\
\text { Standard } \\
\text { Standard - Ca } \ddagger \\
\text { Standard - Ca } \\
\text { Standard - Mg } \\
\text { Standard - Mg } \\
\text { Standard - (Ca }+\mathrm{Mg}) \ddagger \\
\text { Standard - (Ca }+\mathrm{Mg}) \ddagger \\
\text { Standard } \\
\text { Standard }\end{array}$ & $\begin{array}{l}0 \\
+ \\
0 \\
+ \\
0 \\
+ \\
0 \\
+ \\
0 \\
+\end{array}$ & $\begin{array}{r}45 \\
168 \\
72 \\
121 \\
29 \\
190 \\
73 \\
92 \\
19 \\
307\end{array}$ & $\begin{array}{r}123 \\
49 \\
161 \\
19 \\
288\end{array}$ & $\begin{array}{r}264 \\
665 \\
246 \\
488 \\
231 \\
588 \\
60 \\
53\end{array}$ & $\begin{array}{c}401 \\
242 \\
357 \\
-7\end{array}$ \\
\hline
\end{tabular}

* All sacs from midportion of small intestine and about $4 \mathrm{~cm}$ long.

$\dagger$ Standard medium is Krebs-Henseleit bicarbonate, containing $200 \mathrm{mg} \%$ glucose and 5,000 $\mu \mu \mathrm{g} \mathrm{Co}^{60}-\mathrm{B}_{12}$, gassed with $95 \% \mathrm{O}_{2}-5 \% \mathrm{CO}_{2}$ (pH 7.4).

$\ddagger$ Each divalent cation deleted was replaced by an equivalent millimolar concentration of sodium.

studies with rat gut homogenate, except that the gas phase was air.

\section{RESULTS}

Site of intrinsic factor action in the rat small intestine. Figure 1 demonstrates that uptake of vitamin $B_{12}$ mediated by $R I F C$ is greatest in everted sacs from the midportion of the rat small intestine. A relatively high $\mathrm{Co}^{60}-\mathrm{B}_{12}$ uptake by the teminal ileum in the absence of RIFC was observed in three of four separate rat intestines.

Divalent cation dependence of RIFC action. Table I demonstrates that RIFC does not ap-

TABLE II

$p H$ dependence of rat intrinsic factor concentrate in augmenting absorption of $\mathrm{Co}^{57}-B_{12}$ by everted sacs $*$ of rat small intestine

\begin{tabular}{|c|c|c|c|c|}
\hline \multicolumn{2}{|c|}{$\begin{array}{c}\mathrm{pH} \text { of buffered } \\
\text { mediumt }\end{array}$} & \multirow[b]{2}{*}{ RIFC } & \multirow{2}{*}{$\begin{array}{l}\mathrm{cpm} / \\
\text { everted } \\
\text { sac }\end{array}$} & \multirow{2}{*}{$\begin{array}{l}\text { Excess } \\
\text { counts } \\
\text { over } \\
\text { control }\end{array}$} \\
\hline $\begin{array}{l}\text { Before } \\
\text { inc. }\end{array}$ & $\begin{array}{l}\text { After } \\
\text { inc. }\end{array}$ & & & \\
\hline $\begin{array}{l}7.1 \\
7.1 \\
5.7 \\
5.7 \\
5.7 \\
5.7 \\
7.1 \\
7.1 \\
7.1 \\
7.1\end{array}$ & $\begin{array}{l}6.3 \\
6.3 \\
5.7 \\
5.7 \\
6.8 \ddagger \\
6.7 \ddagger \\
5.7 \S \\
5.7 \S \\
6.7 \\
6.8\end{array}$ & $\begin{array}{c}0 \\
+ \\
0 \\
+ \\
0 \\
+ \\
0 \\
+ \\
0 \\
+\end{array}$ & $\begin{array}{r}123 \\
259 \\
102 \\
44 \\
103 \\
299 \\
86 \\
35 \\
78 \\
488\end{array}$ & $\begin{array}{r}136 \\
-58 \\
196 \\
-51 \\
410\end{array}$ \\
\hline
\end{tabular}

* All sacs as in Table I; each filled with $1.1 \mathrm{ml}$ buffered medium at $\mathrm{pH}$ 7.1.

$\dagger$ Buffered external medium in each flask contained 5,000 $\mu \mu g \mathrm{Co}^{57}-\mathrm{B}_{12}$ with a gas phase of $100 \% \mathrm{O}_{2}$.

$\pm 0.085 \mathrm{ml} 0.2 \mathrm{M} \mathrm{NaOH}$ had been added to buffer after first 15 minutes of incubation.

$\S 0.2 \mathrm{ml}$ Tris acid maleate had been added to buffer after first 15 minutes of incubation. preciably enhance vitamin $B_{12}$ uptake by everted sacs of rat small intestine when both calcium and magnesium are deleted from the medium. Deletion of calcium alone appears to reduce markedly the effect of RIFC. Deletion of magnesium alone does not. The finding that deletion of calcium from the incubation medium results in higher radio- $B_{12}$ uptake by control sacs (without RIFC) has been previously noted (1). The calcium and magnesium dependence of RIFC action is also

TABLE III

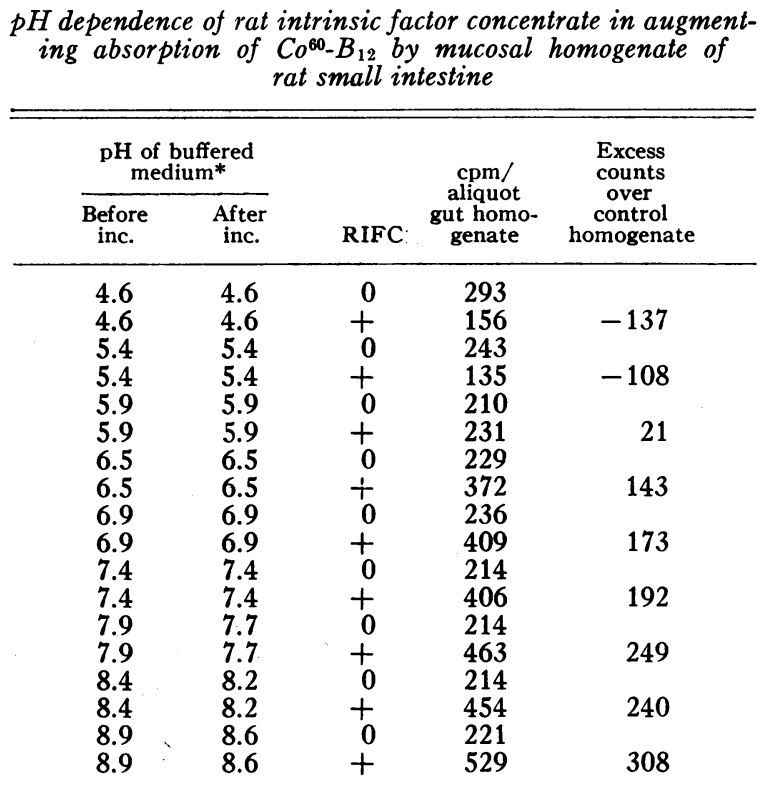

* 5,000 $\mu \mu \mathrm{g} \mathrm{Co}^{60}-\mathrm{B}_{12}$ added to each aliquot of buffered medium. Incubation performed with air as gas phase. 
demonstrable in rat small intestine mucosal homogenate (Table I).

pH dependence of RIFC action. Table II shows that RIFC enhances vitamin $\mathrm{B}_{12}$ uptake by everted sacs of rat small intestine at $\mathrm{pH} 7.1$ but not at $\mathrm{pH} 5.7$. RIFC previously kept at $\mathrm{pH} 5.7$ for 15 minutes at $37^{\circ} \mathrm{C}$ enchances vitamin $\mathrm{B}_{12}$ uptake by everted sacs when the $\mathrm{pH}$ is raised to 6.8 . The enhancing effect of RIFC at $\mathrm{pH} 7.1$ is reversed to one of inhibition by lowering the $\mathrm{pH}$ to 5.7 .

Table III indicates that the enhancing effect of RIFC on vitamin $B_{12}$ uptake by rat small intestine homogenate increases stepwise as the $\mathrm{pH}$ is raised stepwise from 5.9 to 8.9 .

\section{DISCUSSION}

The question of relevance to physiological fact arises with all in vitro systems, and can only be settled in each case by demonstrating that what occurs in vitro also occurs in physiological circumstances in vivo. It has been demonstrated in vivo $(15,16)$ that the major site of absorption of vita$\min \mathrm{B}_{12}$ in the rat is the midportion of the small intestine. Prior studies $(9,17)$, confirmed here (using the entire length of rat small intestine), demonstrate that intrinsic factor-mediated vitamin $\mathrm{B}_{12}$ absorption in everted sacs of rat small intestine is greatest in the same portion of the small intestine. This indicates anatomical and physiological similarities of the in vitro everted sac system to the in vivo system for the absorption of vitamin $\mathrm{B}_{12}$ in the rat. Moreover, in quantitating the sites of vitamin $\mathrm{B}_{12}$ absorption, the in vitro system excludes in vivo variations in the contents of the intestinal lumen, such as distally diminished amounts of intrinsic factor and radioactive vitamin $\mathrm{B}_{12}$ or local differences in $\mathrm{pH}$.

The finding of calcium dependence of intrinsic factor action at $37^{\circ} \mathrm{C}$ in everted sacs of rat small intestine and in rat small intestine homogenate using homologous intrinsic factor also has a counterpart in vivo (2). In man, short-term (18, 19) or long-term $(19,20)$ treatment with calcium-chelating agents appears to inhibit vitamin $\mathrm{B}_{12}$ absorption and eventually to lower serum vitamin $B_{12}$ levels $(19,20)$.

Calcium appears to be essential for binding of intrinsic factor to the hypothetical receptors on the small intestinal mucosa $(1,2)$. It is inter- esting that in Hydra, which requires bound calcium for the action of surface receptors, magnesium antagonizes rather than partially substitutes for the action of calcium (21). The finding that magnesium may partially substitute for calcium was foreshadowed by the evidence that magnesium EDTA was a less potent blocker of RIFC action than was disodium EDTA (2).

The studies of $\mathrm{pH}$ dependence here reported reinforce previous clinical (6) and experimental (7) findings in vivo and in vitro. They demonstrate that RIFC is unable to enhance vitamin $B_{12}$ absorption at $\mathrm{pH} 5.7$, but that a slight rise in $\mathrm{pH}$ to 5.9 or above allows such enhancement. The suppression of ionization of carboxyl groups on mucosal cell surfaces (22) or on mucoproteins (23) by low $\mathrm{pH}$ may be related to the dependence of RIFC adsorption on divalent cations such as $\mathrm{Ca}^{++}$and $\mathrm{Mg}^{++}$. At any rate, it appears that the ineffectiveness of RIFC at $\mathrm{pH} 5.7$ is not due to damage to the molecule, since its enhancement ability is restored on again raising the $\mathrm{pH}$. These findings suggest that a $\mathrm{pH}$ above 5.7 is required for intrinsic factor to attach to receptors on the intestinal mucosa, especially since the enhancing effect of RIFC on vitamin $B_{12}$ uptake by everted sacs of rat small intestine appears to become inhibitory when the $\mathrm{pH}$ of the system is reduced to 5.7. This may be due to a combined effect: the low $\mathrm{pH}$ obliterates the RIFC enhancement and RIFC binds most of the vitamin $B_{12}(2)$, leaving very little free in solution to diffuse into the gut mucosa.

Preliminary experiments (not shown) demonstrated that comparable enhancing effects with RIFC upon $\mathrm{Co}^{60}-\mathrm{B}_{12}$ absorption could be demonstrated in either everted sacs or suspensions or homogenates of mucosal scrapings from the rat small intestine. The homogenate system possesses the advantage that it eliminates variations in the measurement or in the inherent activity of the mucosa of different everted mid-intestinal segments (Figure 1). Consequently, a single aliquot of the mucosal homogenate can serve as a control for a number of experimental flasks. In this respect the intestinal homogenate system has the advantages for RIFC studies that the liver homogenate system (24) possesses for studies $(24,25)$ of hog intrinsic factor concentrate activity. In the intestinal homogenate system, as in 
the liver homogenate system, the intrinsic factor effect is observable at room temperature and at $3^{\circ} \mathrm{C}$, as well as at $37^{\circ} \mathrm{C}$ (data not presented). Since each aliquot of intestinal homogenate is identical with every other aliquot, this system appears to provide a fairly quantitative assay for intrinsic factor activity. Unpublished studies (26) indicate that homogenate prepared from the bottom half of guinea pig small intestine may prove more useful for "assay" of human intrinsic factor activity than the everted sacs of guinea pig small intestine previously (10) suggested.

\section{SUMMARY}

1. Prior in vivo and in vitro findings that the midportion of the small intestine of the rat is the site of vitamin $\mathrm{B}_{12}$ absorption were confirmed in vitro.

2. Calcium is required for rat intrinsic factor concentrate (RIFC) adsorption to everted sacs of rat small intestine or to rat small intestine mucosal homogenate in vitro. Magnesium can partially substitute for calcium.

3. The enhancing effect of RIFC on vitamin $\mathrm{B}_{12}$ absorption occurs at $\mathrm{pH} 5.9$ or higher. It is sharply $\mathrm{pH}$ dependent and at $\mathrm{pH} 5.7$ is reversed to an inhibitory effect.

4. Small intestine mucosal homogenate is a useful tool for studies of intrinsic factor activity and the factors affecting it.

\section{ADDENDUM}

At the Second European Symposium on Vitamin $B_{12}$ and Intrinsic Factor (Hamburg, Germany, August 2-5, 1961) (Proceedings to be published by Ferdinand Enke Verlag, Stuttgart) it was reported by Niewig, Abels, Vegter and Hellemans that sodium bicarbonate enhanced the decreased vitamin $B_{12}$ absorption of two patients with pancreatic insufficiency, presumably by raising the low $\mathrm{pH}$ of the duodenal contents. Their results suggest that our findings in rats in vitro may be applicable to man in vivo.

\section{ACKNOWLEDGMENT}

The authors are indebted to Mrs. Barbara Bean Mummey and Mrs. Rebecca Fisher Dunn for technical assistance.

\section{REFERENCES}

1. Herbert, V. Mechanism of intrinsic factor action in everted sacs of rat small intestine. J. clin. Invest. 1959, 38, 102.
2. Cooper, B. A., and Castle, W. B. Sequential mechanisms in the enhanced absorption of vitamin $B_{12}$ by intrinsic factor in the rat. J. clin. Invest. 1960, 39, 199.

3. Abels, J. Intrinsic factor van Castle en resorptie van vitamine $B_{12}$ (English summary). Groningen, Acad. Proefschrift, 1959.

4. Abels, J., Woldring, M. G., Nieweg, H. O., Faber, J. G., and de Vries, J. A. Ethylencdiamine tetraacetate and the intestinal absorption of vitamin $B_{12}$. Nature (Lond.) 1959, 183, 1395.

5. Rice, E. G., Greenberg, S. M., Herndon, J. F., and Van Loon, E. J. Effect of ethylenediamine tetraacetate on vitamin $B_{12}$ absorption in the rat. $\mathrm{Na}$ ture (Lond.) 1959, 184, 1948.

6. Castle, W. B., Heath, C. W., Strauss, M. B., and Heinle, R. W. Observations on the etiologic relationship of achylia gastrica to pernicious anemia. VI. The site of the interaction of food (extrinsic) and gastric (intrinsic) factors; failure of in vitro incubation to produce a thermostable hematopoietic principle. Amer. J. med. Sci. 1937, 194, 618.

7. Nieweg, H. O., Shen, S. C., and Castle, W. B. Mechanism of intrinsic factor action in the gastrectomized rat. Proc. Soc. exp. Biol. (N. Y.) 1957, 94, 223.

8. Strauss, E. W., and Wilson, T. H. Factors controlling $\mathrm{B}_{12}$ uptake by intestinal sacs in vitro. Amer. J. Physiol. 1960, 198, 103.

9. Strauss, E. W., and Wilson, T. H. Effect of intrinsic factor in vit. $B_{12}$ uptake by rat intestine in vitro. Proc. Soc. exp. Biol. (N. Y.) 1958, 99, 224.

10. Wilson, T. H., and Strauss, E. W. Some species differences in the intrinsic factor stimulation of $B_{12}$ uptake by small intestine in vitro. Amer. J. Physiol. 1959, 197, 926.

11. Wilson, T. H., and Wiseman, G. The use of sacs of everted small intestine for the study of the transference of substances from the mucosal to the serosal surface. J. Physiol. (Lond.) 1954, 123, 116.

12. Krebs, H. A., and Henseleit, K. Untersuchungen über die Harnstoffbildung im Tierkörper. HoppeSelyers Z. physiol. Chem. 1932, 210, 33.

13. Cohen, P. P. Suspending media for animal tissues in Manometric Techniques, 3rd ed., W. W. Umbreit, R. H. Burris and J. F. Stauffer, Eds. Minneapolis, Burgess, 1957, p. 149.

14. Gomori, G. Histochemical demonstration of sites of choline esterase activity. Proc. Soc. exp. Biol. (N. Y.) 1948, 68, 354.

15. Booth, C. C., Chanarin, I., Anderson, B. B., and Mollin, D. L. The site of absorption and tissue distribution of orally administered ${ }^{56} \mathrm{Co}$-labelled vitamin $B_{12}$ in the rat. Brit. J. Haemat. 1957, 3, 253.

16. Reynell, P. C., Spray, G. H., and Taylor, K. B. The site of absorption of vitamin $B_{12}$ in the rat. Clin. Sci. 1957, 16, 663. 
17. Herbert, V., Castro, Z., and Wasserman, L. R. Localization of the effect of intrinsic factor in the rat small intestine in vitro. Clin. Res. 1959, 7, 32.

18. Gräsbeck, R., and Nyberg, W. Inhibition of radiovitamin $B_{12}$ absorption by ethylenediaminetetraacetate (EDTA) and its reversal by calcium ions. Scand. J. clin. Lab. Invest. 1958, 10, 448.

19. Herbert, V. Studies on the role of intrinsic factor in vitamin $B_{12}$ absorption, transport, and storage. Amer. J. clin. Nutr. 1959, 7, 433.

20. Herbert, V. The Megaloblastic Anemias. New York, Grune \& Stratton, 1959.

21. Lenhoff, H. M., and Bovaird, J. Requirement of bound calcium for the action of surface chemoreceptors. Science 1959, 130, 1474.
22. Zeidman, I. Chemical factors in the mutual adhesiveness of epithelial cells. Cancer Res. 1947, 7, 386.

23. Kwart, H., and Shashoua, V. E. The structure and constitution of mucus. Trans. N. Y. Acad. Sci. 1957, 19, 595.

24. Herbert, V., Castro, Z., and Wasserman, L. R. Stoichiometric relation between liver-receptor, intrinsic factor and vitamin $B_{12}$. Proc. Soc. exp. Biol. (N. Y.) 1960, 104, 160.

25. Castro, Z., Herbert, V., and Wasserman, L. R. Blocking of hog intrinsic factor by human gastric juice and certain mucopolysaccharides, including blood group substance. J. clin. Invest. 1961, 40, 66.

26. Sullivan, L. W., Herbert, V., and Castle, W. B. Unpublished studies. 